\title{
Study the Effect of Different Levels of Zucchini (Cucurbita pepo L.) on the Biological Indicators for the Prevention of Cardiovascular Disease in Rats Fed High-Fat Diets
}

\author{
El-Sayeda G. E. El-Sahar', Hala R. A. Sopeah'1, Mona S. Almujaydil² \\ ${ }^{1}$ Home Economic Department, Faculty of Specific Education, Ain Shams University, Cairo, Egypt \\ ${ }^{2}$ Food Sciences and Human Nutrition, College of Agriculture and Veterinary Medicine, Qassim University, Al-Mulida, KSA \\ Email: Dr_sayeda2015@yahoo.com,drhalarashed@yahoo.com
}

How to cite this paper: El-Sahar, El-S.G.E., Sopeah, H.R.A. and Almujaydil, M.S. (2020) Study the Effect of Different Levels of Zucchini (Cucurbita pepo L.) on the Biological Indicators for the Prevention of Cardiovascular Disease in Rats Fed High-Fat Diets. Food and Nutrition Sciences, 11, 63-81.

https://doi.org/10.4236/fns.2020.112007

Received: December 20, 2019

Accepted: February 7, 2020

Published: February 10, 2020

Copyright $\odot 2020$ by author(s) and Scientific Research Publishing Inc. This work is licensed under the Creative Commons Attribution International License (CC BY 4.0).

http://creativecommons.org/licenses/by/4.0/

\begin{abstract}
The effects of fresh zucchini on nutritional status, and biological indicators for the prevention of cardiovascular disease in rats fed high-fat diets investigated in this study. Thirty Sprague Dawley rats were randomly divided into two main groups the first, negative control group $\mathrm{Co}(-)(\mathrm{n}=6)$, fed basal diet, The second group $(\mathrm{n}=24)$ fed high-fat diet (containing basal diet $+5 \%$ tallow $+1 \%$ cholesterol $+0.02 \%$ bile salt). This group was divided into four subgroups each group 6 rats: group positive control co $(+)$ fed high-fat diet only, group 1 (G (1)) fed high-fat diet plus $10 \%$ zucchini, group 2 (G (2) fed high-fat diet plus $15 \%$ zucchini and group 3 (G (3)) fed high-fat diet plus $20 \%$ zucchini. The levels of serum total cholesterol (TC), triglyceride (TG), highdensity lipoprotein cholesterol (HDL-C) and low-density lipoprotein cholesterol (LDL-C) were measured after eight wk. of experimental treatment. The pathologic changes of the heart, spleen and kidney were evaluated. SPSS, one way ANOVA was used to analyze the results. The results indicated that the mean values of body weight gain (BWG) and feed efficiency ratio (FIR) in G (2) and G (3) showed significant decrease compared to co (-), co (+) and G 1. The results showed that in groups (G1, G2 and G3) the relative weight of heart had significant increase when compared with control negative group. But liver and spleen weight had no significant difference when compared with control negative and positive group, the levels of TC, TG and LDL-C were significantly increased in co $(+)(\mathrm{P}<0.05)$ Compared to co $(-)$, all groups fed on high fat diet containing different levels of zucchini (10\%, 15\% and $20 \%)$ had significant decrease in TC and LDL-C compared with co (+), also G2 and G3 had improve significant in HDL-C when compared with co. (+). The
\end{abstract}


groups fed on zucchini give results similar to group co. (-). The best treatment was zucchini (15\% and $20 \%$ ) which had lowest values of total lipid cholesterol and LDL-C, and the best values of HDL-C, HDL-C/TC \% for all groups fed on high fat diet and zucchini increased non significantly $(\mathrm{p} \leq 0.05)$ the HDL-C/TC \% index compared to group co. (+). while, G2 and G3 gave significant decrease in LDL-C/HDL-C ratio compared to group co. (+). Morphologic changes of heart, spleen and kidney revealed that groups G2 and G3 had a similar preventive effect against CHD in this experimental model. In conclusion, results showed that zucchini had similar potential to attenuate CHD-related parameters in a mild oxidative stress induced by high-fat diet in rats.

\section{Keywords}

Atherogenic Index, Cardio Protective, Cucurbita pepo L., High-Fat Diet, HDL-C, LDL-C, Lipid Profile, Zucchini

\section{Introduction}

The public health strategies for the past 20 years, has the principal focus for reducing the risk of coronary heart disease (CHD) has been aimed at decreasing serum cholesterol levels. The implicit basis for clinical cardiovascular disease (CVD) is a collection of thrombosis and atherosclerosis. However, new findings have spotlighted not only cholesterol but also low density lipoprotein (LDL) and triacylglycerol as a significant lipid risk factor for CHD [1]. Heart disease is the main cause of dying for people of most ethnicities [2].

The risk of promoting coronary heart disease (CHD) after age 40 has been predestined to be $32 \%$ for women and $49 \%$ for men [3]. The role of nutrition, to the protection of $\mathrm{CHD}$ is incontestable. Advance in understanding the importance of diet on CHD has developed in the past 100 years. Early evidence came from facts on trends in food consumption and studies which showed associations between spread and fat intake across and within countries [4] [5]. For many years, research then focused on the role of individual nutrient intakes, like cholesterol and saturated fat, through metabolic studies and clinical trials [6] [7].

Until very recently, most studies of diet and CVD focused on dietary lipids. Both associations between fat intake, cholesterol and $\mathrm{CHD}$, and responsiveness of blood cholesterol to changes in dietary fat [8] [9] [10].

More recently, there have been major shifts in nutrition research to understand the role of foods and diet as a whole. Dietary strategies which are able to reduce these circulating lipid levels and offer long-term efficacy comparable with effective drug treatments are currently being sought. One dietary strategy that may benefit the lipid profile involves supplementation of the diet with dietary antioxidant which is naturally present in plant [11].

These plants included Zucchini (Cucurbita pepo L.) that are also known as 
Courgette; belong to the species Cucurbita pepo $L$. This vegetable originated from Italy and can be cultivated easily in temperate climates. Zucchini are mostly made up of water and thus it is very low in calories. According to the USDA National Nutrient Database [12].

The genus Cucurbita includes pumpkin, acorn squash, crooked neck squash, and straight neck squash, all of which contain significant amounts of cucurbitane glycosides and triterpenoid compounds [13]. The folk medicinal properties associated with zucchini are numerous and include treatment for benign prostatic hyperplasia and leprosy [14].

One medium fresh zucchini has 33 calories, 2.37 grams of protein, 6.1 grams of carbohydrate and 2 grams of fiber. Zucchini are also a good source of folic acid, vitamin A, vitamin C, minerals beta-carotene, manganese, zeaxanthin, and lutein. The summer squash also contains antioxidant and anti-inflammatory phytonutrients. Which help rid the body of free radicals and excess inflammation. Zucchini is low in fat and sodium, but high in fiber and potassium. These properties help to maintain healthy blood circulation. Low sodium and high potassium help to maintain healthy blood pressure while fiber, such as the polysaccharide in zucchini, lowers cholesterol levels. Zucchini is believed to possess enzymatic and non- enzymatic antioxidant activities against the buildup of reactive oxygen species (ROS) in the cells [12] [15] [16] [17].

ROS include the singlet oxygen ${ }^{1} \mathrm{O}_{2}$, the superoxide anion $\mathrm{O}_{2}^{-}$, the hydroxyl ion $\mathrm{OH}^{-}$, the peroxide $\mathrm{O}_{2}^{-}$, and the hydrogen peroxide $\mathrm{H}_{2} \mathrm{O}_{2}$. These free radicals cause cellular injuries and initiate peroxidation of polyunsaturated fatty acids in biological membranes [18] [19]. This combination works synergistically to maintain good circulation, which is necessary for healthy blood pressure and a healthy heart. Due to these concerns, it is crucial to focus efforts toward developing more effective to discover natural agents as alternatives to currently available treatments.

This study aimed to study the effects of fresh zucchini on nutritional status, oxidative stress and the atherosclerosis effects in a rat model with mild oxidative stress induced by high-fat diet.

\section{Materials and Methods}

\subsection{Animals Protocols}

Thirty male Sprague Dawley rats, weighting 110 - 120 g were used in this study. They were obtained from the National Research Center (NRC) Dokki Giza Egypt. Animals were clinically healthy and they randomized and housed in stainless steel wire bottom cages ( 3 rats/cage) and maintained in air-conditioned room on a $12 \mathrm{~h} \mathrm{light/dark}$ cycle at $22^{\circ} \mathrm{C}+2^{\circ} \mathrm{C}$ and given the basal diet for one week as an adaptation period before treatments.

\subsection{Preparation of Zucchini}

Zucchini was purchased from the local market, washed then grounded before 
mixing with the diet and added to the basal diet in $100 \mathrm{~g}, 150 \mathrm{~g}$ and $200 \mathrm{~g} / \mathrm{kg}$ diet. During the feeding experiments, animals were daily inspected and food intake was recorded while body weights were recorded according to [20]. The feeding experiment lasted for eight wk.

Tallow was purchased from the local market, then grounded before mixing with the diet and added to the basal diet in $50 \mathrm{~g} / \mathrm{kg}$ diet.

\subsection{Experimental Design}

The animals were distributed into two main groups (Table 1): the first, negative control group Co. $(-)(\mathrm{n}=6)$, fed basal diet [21]. The second group $(\mathrm{n}=24)$ fed high-fat diet (containing basal diet $+5 \%$ tallow $+1 \%$ cholesterol $+0.02 \%$ bile salt). This group was divided into four subgroups: group positive control co. $(+)$ $(\mathrm{n}=6)$ fed high-fat diet only, group $1(\mathrm{G}(1))(\mathrm{n}=6)$ fed high-fat diet plus $10 \%$ zucchini, group $2(\mathrm{G}(2)(\mathrm{n}=6)$ fed high-fat diet plus $15 \%$ zucchini, and group 3 (G (3)) $(\mathrm{n}=6)$ fed high-fat diet plus $20 \%$ zucchini.

The difference between negative control group Co. (-) which fed on basal diet only as Table 1 and group Co. (+) which fed on basal diet addition to $5 \%$ tallow $+1 \%$ cholesterol $+0.02 \%$ bile salt (Table 1 ).

\subsection{Used Chemicals}

Cholesterol as pure white crystalline powder and bile salts as pure yellow powder, were obtained from Elgamhoria Company for Med Preparations Chemicals and Medical Equipment's, Cairo-Egypt.

\subsection{Biological Evaluation}

During the experimental period (8 weeks), the diet consumed was recorded every day. The body weight gain (B.W.G \%) and feed efficiency ratio (F.E.R.) were determined according to [20].

Table 1. Diet composition (\%).

\begin{tabular}{cccccc}
\hline & & \multicolumn{5}{c}{ High fat diet } \\
\cline { 2 - 6 } Negative control (Co. -$)$ & $\begin{array}{c}\text { Positive Control } \\
(\text { Co. }+)\end{array}$ & $\begin{array}{c}\text { Group (1) } \\
\text { G (1) }\end{array}$ & $\begin{array}{c}\text { Group (2) } \\
\text { G (2) }\end{array}$ & $\begin{array}{c}\text { Group (3) } \\
\text { G (3) }\end{array}$ \\
\hline Casein & 15 & 15 & 15 & 15 & 15 \\
Corn oil & 10 & 10 & 10 & 10 & 10 \\
Cellulose & 5 & 5 & 5 & 5 & 5 \\
Vit. Mixture & 1 & 1 & 1 & 1 & 1 \\
Salt mixture & 4 & 4 & 4 & 4 & 4 \\
Tallow & 0 & 5 & 5 & 5 & 5 \\
Cholesterol & 0 & 1 & 1 & 1 & 1 \\
Bile salt & 0 & 0.02 & 0.02 & 0.02 & 0.02 \\
Zucchini & 0 & 0 & 10 & 15 & 20 \\
Corn starch & & & & Up to 100 & \\
\hline
\end{tabular}


At the end of experiment period, animals were sacrificed after $12 \mathrm{~h}$ of fasting then blood samples were collected with care to avoid haemolysis by receiving it on the wall of the tube. Blood samples were collected in clean dry labeled centrifuge tubes and left to clot at room temperature for while, then centrifuged at $3000 \mathrm{rpm}$ for 10 minutes. The clear supernatant serums were aspirated by means of Pasteur pipette and stored at $-20^{\circ} \mathrm{C}$ in Epindorff tubes until used in the biochemical analysis [22]. Serum total cholesterol (TC), triglycerides (TG), high density lipoprotein cholesterol (HDL-C) and low density lipoprotein cholesterol (LDL-C) were determined by using enzymatic colorimetric method [23] [24] [25] [26] [27]. Very low density lipoprotein cholesterol (VLDL-C) were carried out according to Lee and Nieman [27] as follows VLDL-C = TC - LDL-C HDL-C. Atherogenic index (AI) was calculated as HDL-C/TC\% and LDL-C/HDLC [28].

\subsection{Sample Preparation}

The target organs were examined as following: Organs such as heart, liver and kidny were excised and weighed. Then washed in cold saline $(9 \mathrm{~g} / \mathrm{l} \mathrm{NaCl})$, stored in formalin solution (10\%) for $24 \mathrm{r}$ hours. Washing was done in tap water then serial dilutions of alcohol (methyl, ethyl and absolute ethyl) were used for dehydration. Specimens were cleared in xylene and embedded in paraffin at 56 degree in hot air oven for 24 hours. Paraffin bees wax tissue blocks were prepared for sectioning at four microns by slidge microtome. The obtained tissue sections were collected on glass slides, deparffinized and stained by hematoxylin and eosin stains [29]. for histopathological examination through the light microscope.

\subsection{Statistical Analysis}

Statistical Analysis was performed by using computer program, Statistical Package for Social Sciences [30]. Values are given as means \pm SD, and the differences between groups were determined by one way ANOVA. Values of $\mathrm{P}<0.05$ were considered significant.

\section{Results}

\subsection{Effect of Zucchini}

\section{1) Body weight gain, food intake and feed efficiency rate.}

As shown in Table 2, the mean values of initial body weight (IBW) of all experimental groups showed no significant difference. The mean value of final body weight (FBW) in group Co. $(+)(185,20 \pm 5.22 \mathrm{~g})$ was significantly ( $\mathrm{p} \leq$ 0.05 ) higher compared to the corresponding mean values of groups Co. (-), G 1, G 2 and G3 (131 $\pm 2.65,154.6 \pm 4.51,110.4 \pm 3.98$ and $109.2 \pm 3.11$ respectively). The mean values of body weight gain (BWG) and feed efficiency ratio (FIR) in group Co. $(+)$ and group G1 (64.8 \pm 4.6 and $35.6 \pm 2.3$ respectively) was significantly ( $\mathrm{p} \leq 0.05)$ higher when compared with group co $(-)$, while $\mathrm{G}(2)$ and $\mathrm{G}$ (3) showed significant decrease compared to group co (-), group co (+) and G 1. 
Table 2. Body weight gain, food intake and feed efficiency rate of all groups after 8-week feeding.

\begin{tabular}{cccccc}
\hline \multicolumn{2}{c}{ IBW (g) } & FBW (g) & BWG (g) & FI (g) & FER (\%) \\
\hline Co. (-) & $119.20 \pm 3.11$ & $131.00 \pm 2.65$ & $11.80 \pm 1.92$ & $21.60 \pm 3.44$ & $5.48 \pm 0.56$ \\
Co. (+) & $120.40 \pm 3.21$ & $185.20 \pm 5.22^{\mathrm{a}}$ & $64.80 \pm 4.60^{\mathrm{a}}$ & $33.20 \pm 5.50^{\mathrm{a}}$ & $19.83 \pm 2.55^{\mathrm{a}}$ \\
G(1) & $119.00 \pm 2.55$ & $154.60 \pm 4.51^{\mathrm{ab}}$ & $35.60 \pm 2.30^{\mathrm{ab}}$ & $29.00 \pm 2.35^{\mathrm{a}}$ & $12.30 \pm 0.69^{\mathrm{ab}}$ \\
G(2) & $117.00 \pm 2.55$ & $110.40 \pm 3.98^{\mathrm{abc}}$ & $-6.60 \pm 1.52^{\mathrm{abc}}$ & $31.00 \pm 2.45^{\mathrm{a}}$ & $-2.12 \pm 0.39^{\mathrm{abc}}$ \\
G(3) & $120.40 \pm 3.21$ & $109.20 \pm 3.11^{\mathrm{abc}}$ & $-11.20 \pm 4.5^{\mathrm{abc}}$ & $24.40 \pm 2.30^{\mathrm{bd}}$ & $-4.68 \pm 1.80^{\mathrm{abc}}$ \\
\hline
\end{tabular}

Co (-), normal diet; Co (+) high-fat diet; G (1), high-fat diet plus zucchini (10\%); G (2), high-fat diet plus zucchini (15\%); G (3), high-fat diet plus zucchini (20\%); IBW, initial body weight; FBW, final body weight; BWG, body weight gain; FI, food intake; FER, feed efficiency rate. Results are expressed as means \pm SD for $\mathrm{n}=6$ animals per group. Different superscript letter(s) in each column indicate significant differences among groups $(\mathrm{p} \leq 0.05)$.

\section{2) Relative weight of heart, liver and kidney:}

The results showed that in groups (G1, G2 and G3) fed on high fat diet and zucchini the relative weight of heart had significant increase when compared with control negative group. But liver weight had no significant difference when compared with control negative and positive group, However relative kidney weight showed significant increase in G1 $(0.92 \pm 0.19)$ when compared with group co. (+). G2 and G3 showed no significant difference when compared with co. (+) (Table 3).

\section{3) Serum lipid profile:}

Table 4 shows the effect of different levels of zucchini on serum total cholesterol (TC), triglyceride (TG), low density lipoprotein cholesterol (LDL-C), very low density lipoprotein cholesterol (VLDL-C), and high density lipoprotein cholesterol (HDL-C). It could be observed that group co. (+) had significant increase in TC and LDL-C compared with control negative rats. Also, all groups fed on high fat diet containing different levels of zucchini (10\%, 15\% and 20\%) had significant decrease in TC and LDL-C compared with control positive group of rats, also could be observed that G2 and G3 fed on high fat diet containing levels of zucchini (15\% and 20\%) had improve significant in HDL-C (48.0 \pm 5.48 and $46.2 \pm 4.82$ respectively) when compared with control positive group co. (+). The groups fed on zucchini give results similar to group co. (-). The best treatment was zucchini (15\% and 20\%) which had lowest values of total lipid cholesterol and LDL-C, and the best values of HDL-C.

\section{4) atherogenic indices:}

Table 5 shows the comparative change among groups in HDL-C/TC \% and LDLC/HDL-C ratio as atherogenic indices. The low LDL-C/HDL-C ratio indicates low risk of coronary heart disease (CHD), while the high HDL-C/TC \% ratio reflects the low risk of (CHD). The changes of HDL-C/TC \% for all groups fed on high fat diet and zucchini increased non significantly $(\mathrm{p} \leq 0.05)$ the HDL-C/TC \% index compared to group co. $(+)$, however no significant difference was noticed in this index between these groups, this results reflects the low 
Table 3. Relative weight of heart, liver and kidney.

\begin{tabular}{cccc}
\hline Groups & Heart weight $(\mathrm{g})$ & Liver weight $(\mathrm{g})$ & Kidney weight $(\mathrm{g})$ \\
\hline Co. $(-)$ & $0.30 \pm 0.07$ & $2.56 \pm 0.59$ & $0.74 \pm 0.21$ \\
Co. $(+)$ & $0.29 \pm 0.06$ & $3.00 \pm 0.57$ & $0.73 \pm 0.15$ \\
G1 & $0.34 \pm 0.05^{\mathrm{b}}$ & $2.69 \pm 0.25$ & $0.92 \pm 0.19^{\mathrm{b}}$ \\
G2 & $0.36 \pm 0.04^{\mathrm{b}}$ & $2.83 \pm 0.45$ & $0.76 \pm 0.08$ \\
G3 & $0.38 \pm 0.08^{\mathrm{b}}$ & $3.24 \pm 0.55$ & $0.73 \pm 0.08$ \\
\hline
\end{tabular}

Results are expressed as means \pm SD for $n=6$ animals per group. Different superscript letter(s) in each column indicate significant differences among groups $(\mathrm{p} \leq 0.05)$.

Table 4. Effect of zucchini on serum lipid profile in rats after 8 weeks.

\begin{tabular}{cccccc}
\hline Groups & $\begin{array}{c}\text { TC } \\
(\mathrm{mg} / \mathrm{dl})\end{array}$ & $\begin{array}{c}\text { TG } \\
(\mathrm{mg} / \mathrm{dl})\end{array}$ & $\begin{array}{c}\text { HDL-C } \\
(\mathrm{mg} / \mathrm{dl})\end{array}$ & $\begin{array}{c}\text { LDL-C } \\
(\mathrm{mg} / \mathrm{dl})\end{array}$ & $\begin{array}{c}\text { VLDL-C } \\
(\mathrm{mg} / \mathrm{dl})\end{array}$ \\
\hline Co. $(-)$ & $76.00 \pm 15.70$ & $68.20 \pm 9.78$ & $48.40 \pm 9.74$ & $13.60 \pm 10.3$ & $14.00 \pm 1.871$ \\
Co. (+) & $152.00 \pm 38.75^{\mathrm{a}}$ & $94.20 \pm 18.77$ & $35.20 \pm 10.62$ & $97.60 \pm 39.33^{\mathrm{a}}$ & $19.20 \pm 3.56$ \\
G1 & $130.40 \pm 28.61^{\mathrm{a}}$ & $86.20 \pm 22.48$ & $42.20 \pm 12.80$ & $70.60 \pm 22.51^{\mathrm{a}}$ & $17.60 \pm 4.22$ \\
G2 & $124.00 \pm 28.64$ & $137.80 \pm 91.94^{\mathrm{a}}$ & $48.00 \pm 5.48^{\mathrm{b}}$ & $48.40 \pm 43.22$ & $27.60 \pm 17.91$ \\
G3 & $127.20 \pm 26.44$ & $160.80 \pm 49.64^{\mathrm{a}}$ & $46.20 \pm 4.82^{\mathrm{b}}$ & $49.20 \pm 24.22$ & $31.80 \pm 10.04^{\mathrm{a}}$ \\
\hline
\end{tabular}

Results are expressed as means \pm SD for $\mathrm{n}=6$ animals per group. Different superscript letter(s) in each column indicate significant differences among groups $(\mathrm{p} \leq 0.05)$.

Table 5. Effect of zucchini on atherogenic indices.

\begin{tabular}{ccc}
\hline Groups & HDL-C/TC $\%$ & LDL-C/HDL-C \\
\hline C (-) & $64.14 \pm 8.01$ & $0.28 \pm 0.23$ \\
C (+) & $24.79 \pm 11.96^{\mathrm{a}}$ & $3.12 \pm 1.74^{\mathrm{a}}$ \\
G1 & $32.37 \pm 5.64^{\mathrm{a}}$ & $1.72 \pm 0.56$ \\
G2 & $40.27 \pm 9.34^{\mathrm{a}}$ & $1.02 \pm 0.96^{\mathrm{b}}$ \\
G3 & $37.51 \pm 7.56^{\mathrm{a}}$ & $1.07 \pm 0.59^{\mathrm{b}}$
\end{tabular}

Results are expressed as means \pm SD for $n=6$ animals per group. Different superscript letter(s) in each column indicate significant differences among groups $(\mathrm{p} \leq 0.05)$.

risk of CHD. On the other hand the groups fed on high fat diet and zucchini G2 and G3 gave significant decrease in LDL-C/HDL-C ratio compared to group co. $(+)$. Group 2 showed the lowest LDL-C/HDL-C ratio compared to co. (+). The result for group co. $(+)$ was significantly higher than that of co. $(-)$ in parallel with the protective effect, also the value of LDL-C/HDL-C for G2 showed a highly significant $(\mathrm{p} \leq 0.05)$ decrease compared with co. $(-)$.

\subsection{Histopathological Findings}

1) Morphologic changes of rat heart stained with hematoxylin and eosin:

Representative heart sections stained with hematoxylin and eosin in each group are shown in Figures 1-5 the heart in the control rat of group Co. (-) 


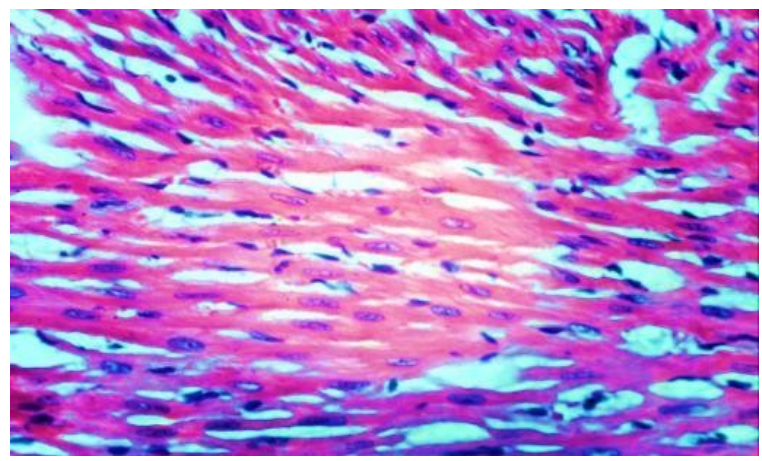

Figure 1. Heart of rat from group Co. (-) Showing no histopathological changes (H \& E $\times 400)$.

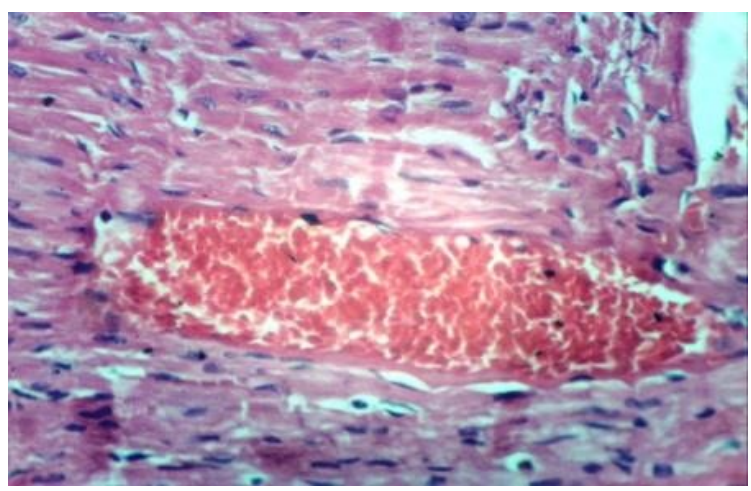

Figure 2. Heart of rat from group Co. $(+)$ showing intermuscular oedema with inflammatory cells infiltration $(\mathrm{H} \& \mathrm{E} \times 400)$.

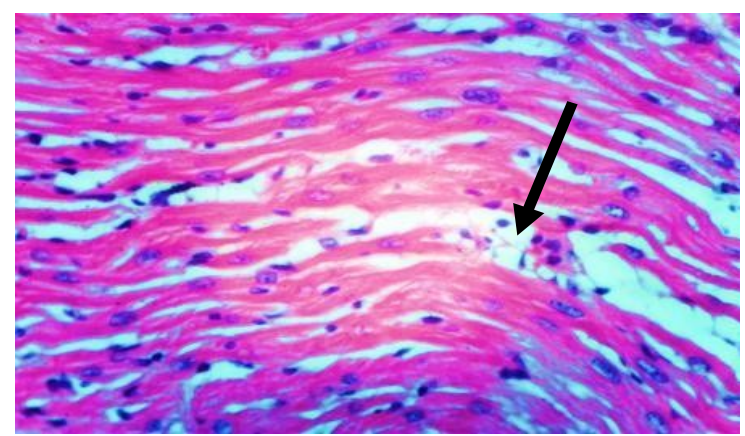

Figure 3. Heart of rat from group 1 showing slight intermuscular oedema $(\mathrm{H} \& \mathrm{E} \times 400)$.

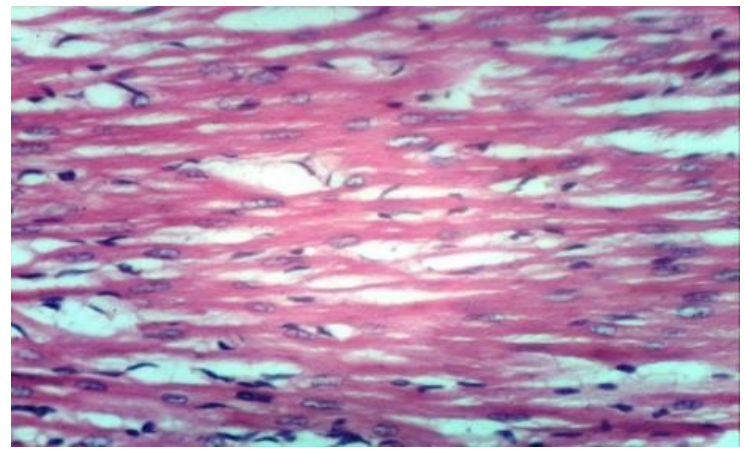

Figure 4. Heart of rat from group 2 showing no histopathological changes ( $\mathrm{H} \& \mathrm{E} \times 400)$. 


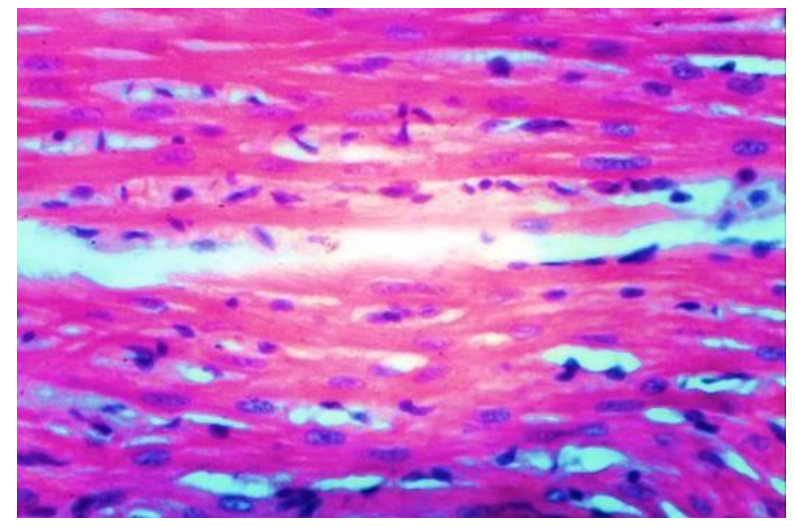

Figure 5. Heart of rat from group 3 showing no histopathological changes $(\mathrm{H} \& \mathrm{E} \times 400)$.

(Figure 1) showed no histopathological alteration and the normal histological structure of the myocardium. Heart of rat in group Co. (+) (Figure 2) revealed slight intermuscular edema deposition of fat in pericardium with inflammatory cells infiltration, while in group 1 (Figure 3) slight intermuscular edema. On the other hand, heart of rat in group 2 and group 3 (Figure 4 and Figure 5) showed histopathological alteration and the normal histological structure of the myocardium. The morphologic features of heart in the rats of group 2 and 3 were closed to that of the control rats group Co. (-), which indicated a similar preventive effect of Zucchini in the development of atherosclerosis in this experimental model.

2) Morphologic changes of rat liver stained with hematoxylin and eosin:

Representative liver sections stained with hematoxylin and eosin in each group are shown in Figures 6-10. The liver in the control rat of group Co. (-) (Figure 6) showing the normal histological structure of hepatic lobule. Liver of rat in group Co $(+)$ (Figure 7) revealed Kupffer cells activation, found a similar result in group 1 (Figure 8). On the other hand, liver of rat in group 2 (Figure 9) Showing Kupffer cells activation and cytoplasmic vacuolization of hepatocytes, group 3 (Figure 10) showed Kupffer cells activation and congestion of central vein. The morphologic features of liver in the rats of $G 1$ and $G 3$ were closed to that of the control rats group Co. (-), which indicated a similar preventive effect of Zucchini in this experimental model.

3) Morphologic changes of rat kidney stained with hematoxylin and eosin:

Representative kidney sections stained with hematoxylin and eosin in each group are shown in Figures 11-15, kidney of rat in group Co. (+) (Figure 12) revealed cystic dilatation of renal tubules and atrophy of some glomerular tuft, the kidney in the control rat of group Co. (-) (Figure 11) showing the normal histological structure of renal parenchyma, found a similar result in the experimental groups (Figures 13-15) the morphologic features of kidney in the rats of group 1 and 3 were closed to that of the control rats group Co. (-), which indicated a similar preventive effect of Zucchini. 


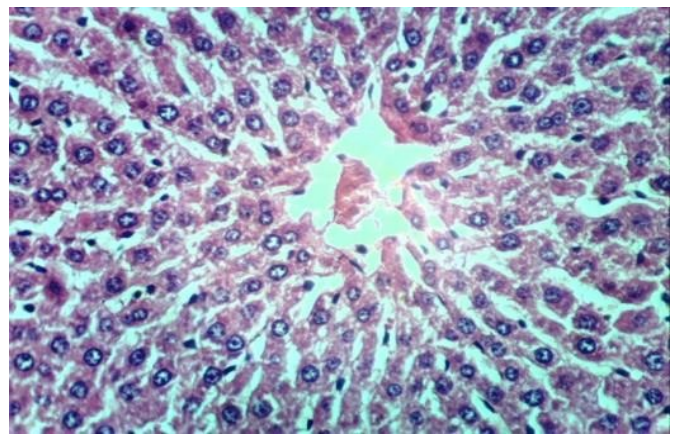

Figure 6. Liver of rat from group Co. (-) showing the normal structure of hepatic lobule $(\mathrm{H} \& \mathrm{E} \times 400)$.

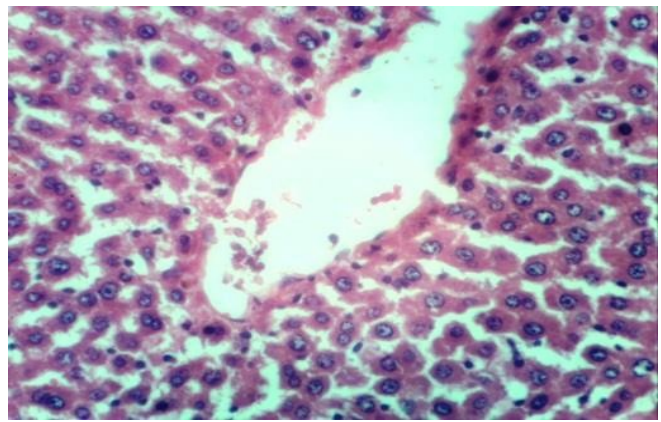

Figure 7. Liver of rat from group Co. $(+)$ showing Kupffer cells histological activation $(\mathrm{H}$ $\& \mathrm{E} \times 400)$.

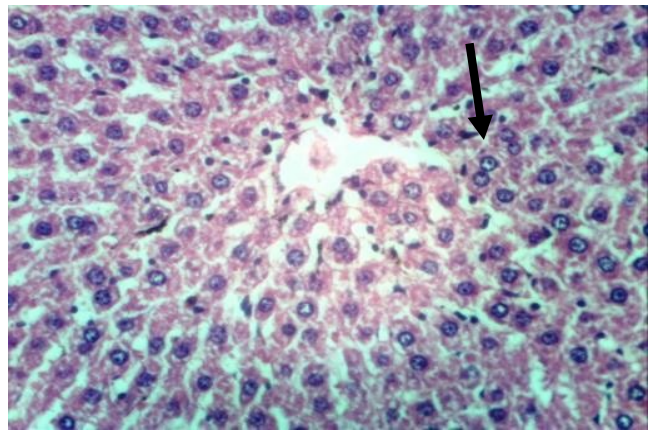

Figure 8. Liver of rat from group 1 showing Kupffer cells activation $(\mathrm{H} \& \mathrm{E} \times 400)$.

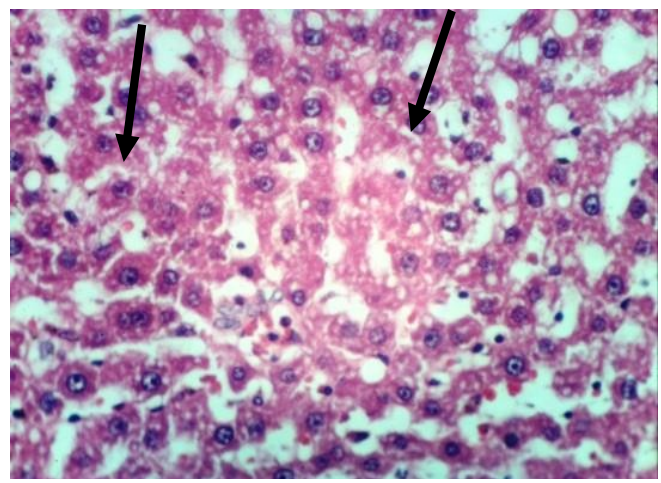

Figure 9. Liver of rat from group 2 showing Kupffer cells activation and cytoplasmic vacuolization of hepatocytes. 


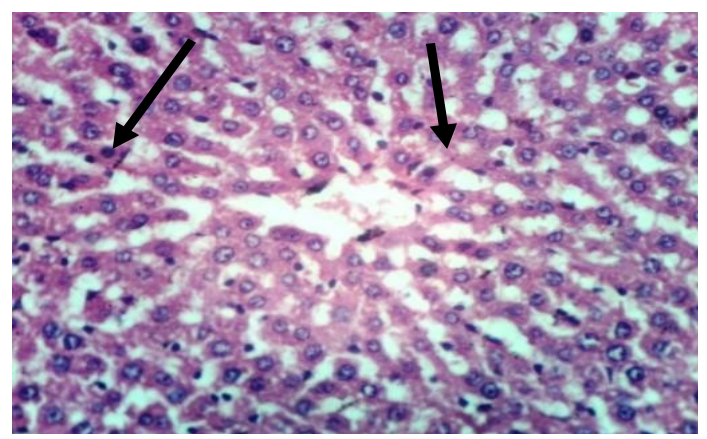

Figure 10. Liver of rat from group 3 showing Kupffer cells activation $(\mathrm{H} \& \mathrm{E} \times 400)$.

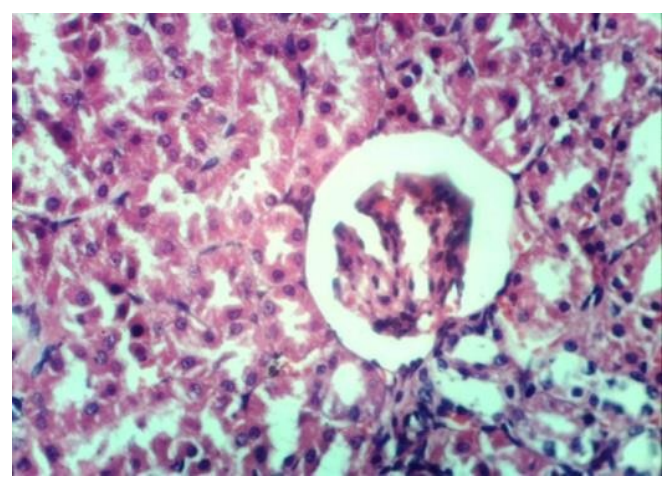

Figure 11. Kidney of rat from group Co. (-) showing the normal histological structure of renal parenchyma $(\mathrm{H} \& \mathrm{E} \times 400)$.

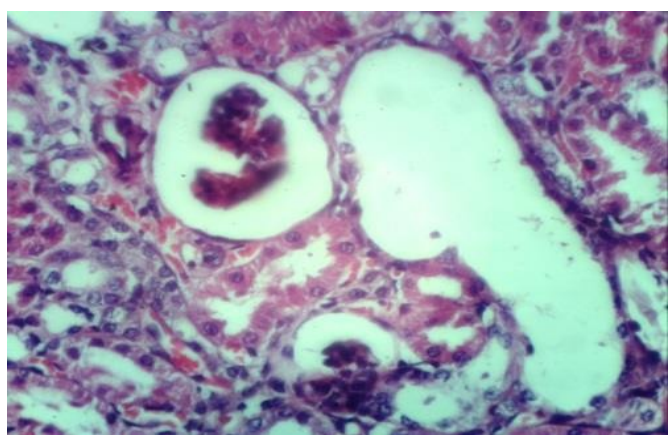

Figure 12. Kidney of rat from group Co. (+) showing cystic dilatation of renal tubules and atrophy of some glomerular tuft $(\mathrm{H} \& \mathrm{E} \times 400)$.

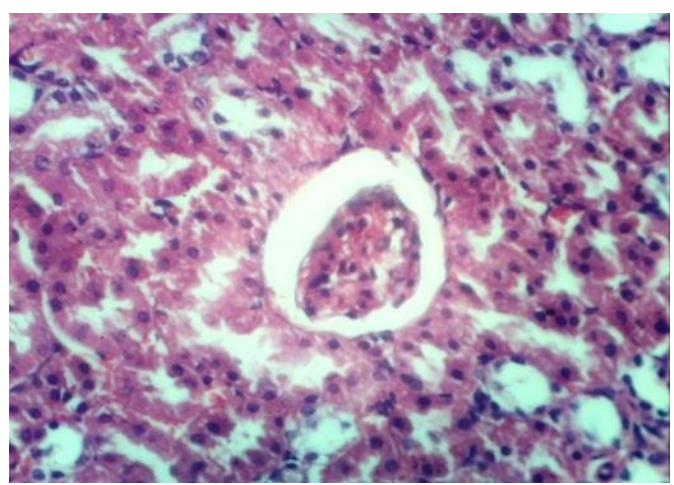

Figure 13. Kidney of rat from group 1 showing normal renal parenchyma $(\mathrm{H} \& \mathrm{E} \times 400)$. 


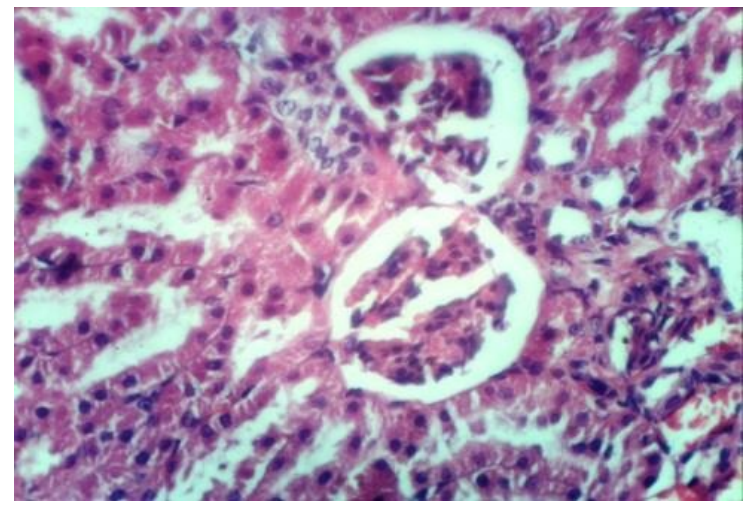

Figure 14. Kidney of rat from group 2 showing no histopathological changes $(\mathrm{H} \& \mathrm{E} \times$ 400).

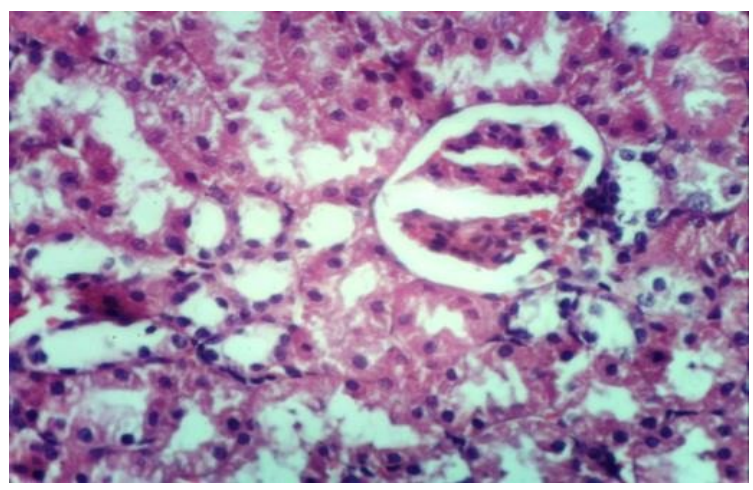

Figure 15. Kidney of rat from group 3 showing no histopathological changes $(\mathrm{H} \& \mathrm{E} \times$ 400).

\section{Discussion}

There is now evidence that dietary factors influence risk of coronary heart disease (CHD) both favorably and unfavorably [31] [32] [33] [34]. The three most atherogenic dietary risk factors are cholesterol, saturated fat and obesity [35]. The free radical theory of aging, first posited by Harman [36] has long provided a biological basis for the progression of chronic disease. Because of its role as a free radical scavenger, zucchini contains of vitamin $\mathrm{C}$ has been hypothesized to have a preventive role in CVD.

Strongest effects were seen with regular consumption of zucchini [37]. In the Beta-carotene Cancer Prevention (ATBC) study, there was a protective effect of zucchini intake on CHD mortality. Summer squash (Cucurbita pepo subsp. pe$p o$ ) is a seasonal vegetable that contains a number of beneficial micronutrients such as minerals, carotenoids, vitamin C, phenolic compounds, etc. [38] [39] [40]. It has been used in traditional folk medicine to treat colds and alleviate aches, due to its antioxidant/anti-radical, anti-carcinogenic, anti-inflammatory, antiviral, antimicrobial and analgesic activities [41] [42] [43] [44] [45]. Therefore zucchini was chosen as a research target

With study the effect of different levels of zucchini (Cucurbita pepo L.) on the Biological Indicators for the Prevention of Cardiovascular Disease in Rats Fed 
High-Fat Diets. The results of this study showed that the final body weight after 8 weeks in group Co.(+) was significantly higher compared to the corresponding values of groups Co. (-), G 1, G 2 and G3. The body weight gain (BWG) and feed efficiency ratio (FIR) in group Co. $(+)$ and group G1was significantly $(\mathrm{p} \leq$ 0.05 ) higher when compared with group co. (-), while G (2) and G (3) showed significant decrease compared to group co (-), group co. (-) and G 1 . These results indicated that zucchini can cause weight loss, which my lead to decrease in the risk of cardiovascular disease, zucchini contains proteins, fibers, polysaccharides and minerals (iron, zinc, manganese, copper, etc.) [46] [47]. Pectin, a major component of plant cell walls, it is a water-soluble fiber found abundantly in zucchini plants [48]. Subsequently, high-fiber diets have also been associated with reduced risk of obesity [49] [50] [51].

Among plasma lipoproteins, LDL-C has a crucial role in inducing atherosclerosis and it has been identified as an independent risk factor for coronary heart disease [35] [52] [53] [54]. while HDL-C levels are inversely related to coronary heart disease [55]. Results obtained in this study indicated that administration of zucchini for 8 weeks in rats fed on high fat diet significantly reduced cholesterol, triglyceride and LDL-C as compared to positive control group. In addition, zucchini was found to increase HDL-C levels.

This finding was in agreement with the results that cholesterol and triglyceride levels significantly increased in diabetic control group as compared to the normal control group. Administration of high dose C. pepo $(2 \mathrm{~g} / \mathrm{kg})$ to diabetic rats significantly reduced cholesterol levels as compared to diabetic control group. Similar to glibenclamide consumption of both high and low dose C. pepo significantly reduced triglyceride levels as compared to diabetic control group. In addition, this plant was found to increase blood insulin and HDL levels, although this was not significant [56].

The lipid reducing effects of $C$. pepo is probably due to its fibers. These substances reduce plasma LDL levels by inhibiting the absorption of cholesterol and bile acids and improvement the activity of LDL receptors. Moreover, a fiber-rich diet increases levels of triglyceride by suppressing lipogenesis in the liver [57] [58]. The presence of unsaturated fatty acids reduces cholesterol levels in rats [59]. The lipid-reducing properties of this plant are partly attributed to the pectin present in it. Previous data suggest that diets rich in pectin facilitate excretion of bile acids which lead to their synthesis increase from cholesterol in the liver and ultimately reduction of blood cholesterol levels [60]. Pectin enhances the activity of lipoprotein lipase in fat tissue and heart, resulting in higher absorption of triglyceride rich lipoproteins (very low density lipoprotein (VLDL) and chylomicron) in tissues other than liver to enhance their collapse and thus decrease triglyceride levels [61]. Since cholesterol plays a crucial role in lipoprotein biosynthesis and LDL's contain the highest level of cholesterol, LDL is likely to deplete following a reduction in cholesterol levels. On the other hand, LDL reduction may be due to an increase in LDL catabolism. By regulating LDL receptor 
gene, flavonoids increase the number of LDL receptors on the surface of liver cells. Following recognition and attachment of LDL apoprotein to LDL receptors, LDL is driven into the hepatocyte and removed from the blood stream [62]. These finding provides a theoretical rationale for the use of zucchini as a preventive agent in atherosclerosis.

Low LDL-C/HDL-C ratio indicates low risk of coronary heart disease (CHD), while high HDL-C/TC \% reflects low risk of CHD [55]. The results of this study in rat model on the high-fat diet showed that zuchini had the same effects in HDL-C/TC \% and LDL-C/HDL-C ratio. It had significantly increased HDL-C/ TC $\%$, whereas significantly decreased LDL-c/HDL-c ratio compared to rats fed high-fat diet. However, HDL-C/TC \% was not significantly different in the control group compared to the treatment groups, but LDLC/HDL-C ratio was significantly lower in rats fed on zucchini compared to that in control group. This finding agreed with the study of Asgary [56] which had shown that a dietary intake of zucchini is associated with a decreased risk of chronic diseases such as cardiovascular disease. Also, demonstrated that zucchini has enzymatic antioxidants are equally important in protecting organisms against free radical buildup. Enzymatic antioxidants, such as superoxide dismutase, protect cells and $t$ issues from oxidative damage by reactive oxygen species. Superoxide dismutase (SOD), peroxidases (PO) and catalases (Cat) are some of the enzymatic antioxidative defense mechanisms. Zucchini extracts showed higher SOD activity [63].

Zucchini had important role in nutrition human and his health secure due to this fruit and its components were safe, accomplished to inhibit significantly the $\mathrm{H}_{2} \mathrm{O}_{2}$-induced damage and exhibit anti-proliferative and pro-apoptotic activities [64].

\section{Conclusions}

In conclusion, this research is characterized by the use of three different ratios of zucchini to determine the most effective percentage and study the extent of its effective influence on the prevention of heart disease and the dangers of excessive consumption of fats as well as morphological examination of the tissues of the heart, liver and kidneys. Which indicated preventive effect of Zucchini in rat model, zucchini can cause weight loss at $15 \%$ and $20 \%$, which my lead to decrease in the risk of cardiovascular disease. Also, zucchini had protective effect in reducing the extent of Serum lipid profiles (TC, TG, LDL-C and VLDL-C) and increase HDL-C levels, It had significantly increased HDL-C/TC \%, whereas significantly decreased LDLc/HDL-c ratio compared to rats fed high-fat diet. But LDLC/HDL-C ratio was significantly lower in rats fed on zucchini.

The result of the present investigation is quite encouraging and the effect which is further enhanced by its antioxidant properties. The zucchini fruit showed promising results, and could play a beneficial role in human nutrition and general health. We conclude that $C$. pepo and their components were safe, able to 
hypolipedemia. However, further studies in detail are warranted to explore its active ingredients responsible for the beneficial action and the mechanisms involved. Controlled clinical trials are also strongly needed to confirm the Prevention of Cardiovascular disease effects in human subjects. These are our focus for future studies.

\section{Conflicts of Interest}

The authors declare no conflicts of interest regarding the publication of this paper.

\section{References}

[1] Mangiapane, E.H. and Salter, A.M. (1999) Diet, Lipoproteins and Coronary Heart Disease. A Biochemical Perspective. Nottingham University Press, Nottingham.

[2] Center for Disease Control and Prevention (2010) Heart Disease Facts. Center for Disease Control and Prevention, Atlanta, GA.

[3] Lloyd-Jones, D.M., Larson, M.G., Beiser, A. and Levy, D. (1999) Lifetime Risk of Developing Coronary Heart Disease. The Lancet, 353, 89-92. https://doi.org/10.1016/S0140-6736(98)10279-9

[4] Keys, A., Menotti, A., Karvonen, M.J., et al. (1986) The Diet and 15-Year Death Rate in the Seven Countries Study. American Journal of Epidemiology, 124, 903-915. https://doi.org/10.1093/oxfordjournals.aje.a114480

[5] Slattery, M.L. and Randall, D.E. (1988) Trends in Coronary Heart Disease Mortality and Food Consumption in the United States between 1909 and 1980. The American Journal of Clinical Nutrition, 47, 1060-1067. https://doi.org/10.1093/ajcn/47.6.1060

[6] Frantz Jr., I.D., Dawson, E.A., Ashman, P.L., et al. (1989) Test of Effect of Lipid Lowering by Diet on Cardiovascular Risk. Arteriosclerosis, 9, 129-135. https://doi.org/10.1161/01.ATV.9.1.129

[7] Turpeinen, O., Karvonen, M.J., Pekkarinen, M., Miettinen, M., Elosuo, R. and Paavilainen, E. (1979) Dietary Prevention of Coronary Heart Disease: The Finnish Mental Hospital Study. International Journal of Epidemiology, 8, 99-118. https://doi.org/10.1093/ije/8.2.99

[8] Aravanis, C., Corcondilas, A., Dontas, A.S., Lekos, D. and Keys, A. (1970) Coronary Heart Disease in Seven Countries. IX. The Greek Islands of Crete and Corfu. Circulation, 41, I88-I100. https://doi.org/10.1161/01.CIR.41.4S1.I-88

[9] Blackburn, H., Taylor, H.L. and Keys, A. (1970) Coronary Heart Disease in Seven Countries. XVI. The Electrocardiogram in Prediction of Five-Year Coronary Heart Disease Incidence among Men Aged Forty through Fifty-Nine. Circulation, 41, I154-I161. https://doi.org/10.1161/01.CIR.41.4S1.I-154

[10] Taylor, H.L., Blackburn, H., Keys, A., Parlin, R.W., Vasquez, C. and Puchner, T. (1970) Coronary Heart Disease in Seven Countries. IV. Five-Year Follow-Up of Employees of Selected U.S. Railroad Companies. Circulation, 41, I20-I39. https://doi.org/10.1161/01.CIR.41.4S1.I-20

[11] Blum, A., Monir, M., Wirsansky, I. and Ben-Arzi, S. (2005) The Beneficial Effects of Tomatoes. European Journal of Internal Medicine, 16, 402-404. https://doi.org/10.1016/j.ejim.2005.02.017

[12] USDA (2014) United States Department of Agriculture. http://fnic.nal.usda.gov/ 
[13] Radford, A., Ahles, H. and Bell, C. (1968) Manual of the Vascular Flora of the Carolinas. The University of North Carolina Press, Chapel Hill, NC.

[14] Dhiman, K., Gupta, A., Sharma, D., Gill, N. and Goyal, A. (2012) A Review on the Medicinally Important Plants of the Family Cucurbitaceae. Asian Journal of Clinical Nutrition, 4, 16-26. https://doi.org/10.3923/ajcn.2012.16.26

[15] Dasgupta, N. and De, B. (2006) Antioxidant Activity of Some Leafy Vegetables of India: A Comparative Study. Food Chemistry, 101, 471-474. https://doi.org/10.1016/j.foodchem.2006.02.003

[16] Wu, S. and Ng, L. (2008) Antioxidant and Free Radical Scavenging Activities of Wild Bitter Melon (Momordica charantia Linn. var. abbreviata Ser.) in Taiwan. LWTFood Science and Technology, 41, 323-330. https://doi.org/10.1016/j.lwt.2007.03.003

[17] Xanthopoulou, M., Nomikos, T., Fragopoulou, E. and Antonopoulou, S. (2009) Antioxidant and Lipoxygenase Inhibitory Activities of Pumpkin Seed Extracts. Food Research International, 42, 641-646. https://doi.org/10.1016/j.foodres.2009.02.003

[18] Palma, J.M., Sandalio, L.M., Corpas, F.J., Romero-Puertas, M.C., McCarthy, I. and Del Rio, L.A. (2002) Plant Proteases, Protein Degradation, and Oxidative Stress: Role of Peroxisomes. Plant Physiology and Biochemistry, 40, 521-530. https://doi.org/10.1016/S0981-9428(02)01404-3

[19] Breusegem, F. and Dat, J. (2006) Reactive Oxygen Species in Plant Cell Death. Plant Physiology, 141, 384-390. https://doi.org/10.1104/pp.106.078295

[20] Chapman, D.G., Castilla, R. and Campbell, J.A. (1959) Evaluation of Protein in Food. Method for the Determination of Protein Efficiency Ratio. Canadian Journal of Biochemistry and Physiology, 1, 679-686. https://doi.org/10.1139/059-074

[21] AIN-American Institute of Nutrition (1993) Purified Diet for Laboratory Rodent, Final Report. The Journal of Nutrition, 123, 1939-1951.

[22] Drury, R.A. and Wallington, E.A. (2012) Carlton's Histological Technique. 5th Edition, Oxford University, Oxford

[23] NIHP-National Institute of Health Publication (1987) Detection, Evaluation and Treatment of High Cholesterol in Adult. No. 88, 292.

[24] Young and Pestaner (1975) Determination of Triglycerides. Bincon Diagnostics, Germany. Annals of Clinical Biochemistry, 21, 25.

[25] Fendewaid, W.T. (1972) Determination of HDL. Clinical Chemistry, 18, 499-503.

[26] Gordon, T. and Amer, M. (1977) Determination of HDL. Journal of Medicine, 63, 707-709.

[27] Lee, R. and Nieman, D. (1996) Nutritional Assessment. 2nd Edition, Mosby Missouri, USA.

[28] Castelli, W.P., Abbott, R.D. and McNamara, P.M. (1983) Summary Estimates of Cholesterol Used to Predict Coronary Heart Disease. Circulation, 67, 730-734.

[29] Bancraft, I.D. (1975) Histochemical Techniques. 2nd Edition, Butter Worths, London, 86-87.

[30] SPSS (1998) Statistical Pakage for Social Science, Computer Software. Version 10, SPSS Company, London, UK.

[31] National Academy of Sciences (NAS) (1989) Diet and Health. National Academy Press, Washington DC.

[32] National Cholesterol Education Program (NCEP) (1990) Report of the Expert Panel on Population Strategies for Blood Cholesterol Reduction. US Department of Health and Human Services, Bethesda, MD, NIH Publication 90-3046. 
[33] The Nutrition Committee, American Heart Association (1996) Dietary Guidelines for Healthy American Adults. Circulation, 94, 1795-1800. https://doi.org/10.1161/01.CIR.94.7.1795

[34] LSRO (Life Sciences Research Office) (1987) Physiological Effects and Health Consequences of Dietary Fiber. Federation of American Societies for Experimental Biology, Bethesda, MD, 236.

[35] NCEP (2002) Third Report of the National Cholesterol Education Program Expert Panel on Detection, Evaluation, and Treatment of High Blood Cholesterol in Adults (Adult Treatment Panel III). Final Report. Circulation, 106, 3143-3421. https://doi.org/10.1161/circ.106.25.3143

[36] Harman, D. (1956) Aging: A Theory Based on Free Radical and Radiation Chemistry. Journal of Gerontology, 11, 298-300. https://doi.org/10.1093/geronj/11.3.298

[37] Gaziano, J.M., Manson, J.E., Branch, L.G., Colditz, G.A., Willett, W.C. and Buring, J.E. (1995) A Prospective Study of Consumption of Carotenoids in Fruits and Vegetables and Decreased Cardiovascular Mortality in the Elderly. Annals of Epidemiology, 5, 255-260. https://doi.org/10.1016/1047-2797(94)00090-G

[38] Blanco-Díaz, M.T., Del Río-Celestino, M., Martínez-Valdivieso, D. and Font, R. (2014) Use of Visible and Near-Infrared Spectroscopy for Predicting Antioxidant Compounds in Summer Squash (Cucurbita pepo ssp pepo). Food Chemistry, 164, 301-308. https://doi.org/10.1016/j.foodchem.2014.05.019

[39] Martínez-Valdivieso, D., Font, R., Gómez, P., Blanco-Díaz, T. and Río-Celestino, D. (2014) Determining the Mineral Composition in Cucurbita pepo Fruit Using near Infrared Reflectance Spectroscopy. Journal of the Science of Food and Agriculture, 94, 3171-3180. https://doi.org/10.1002/jsfa.6667

[40] Martínez-Valdivieso, D., Gómez, P., Font, R. and Del Río-Celestino, M. (2015) Mineral Composition and Potential Nutritional Contribution of 34 Genotypes from Different Summer Squash Morphotypes. European Food Research and Technology, 240, 71-81. https://doi.org/10.1007/s00217-014-2308-7

[41] Menéndez, A., Capó, J.T., Menéndez Castillo, R.A., González, O.L., Domínguez, C.C. and Sanabria, M.L.G. (2006) Evaluation of Cucurbita pepo L. Lipophilic Extract on Androgen-Induced Prostatic Hyperplasia. Revista Cubana de Plantas Medicinales, 11, 1-6.

[42] Møller, P. and Loft, S. (2004) Interventions with Antioxidants and Nutrients in Relation to Oxidative DNA Damage and Repair. Mutation Research/Fundamental and Molecular Mechanisms of Mutagenesis, 551, 79-89. https://doi.org/10.1016/j.mrfmmm.2004.02.018

[43] Oloyede, F., Agbaje, G.O., Obuotor, E.M. and Obisesan, I.O. (2012) Nutritional and Antioxidant Profiles of Pumpkin (Cucurbita pepo Linn.) Immature and Mature Fruits as Influenced by NPK Fertilizer. Food Chemistry, 135, 460-463. https://doi.org/10.1016/j.foodchem.2012.04.124

[44] Shokrzadeh, M., Azadbakht, M., Ahangar, N., Hashemi, A. and Saravi, S.S. (2010) Cytotoxicity of Hydro-Alcoholic Extracts of Cucurbita pepo and Solanum nigrum on HepG2 and CT26 Cancer Cell Lines. Pharmacognosy Magazine, 6, 176-179. https://doi.org/10.4103/0973-1296.66931

[45] Wang, D.C., Pan, H.Y., Deng, X.M., Xiang, H., Gao, H.Y., Cai, H. and Wu, L.J. (2007) Cucurbitane and Hexanorcucurbitane Glycosides from the Fruits of Cucurbita pepo cv dayangua. Journal of Asian Natural Products Research, 9, 525-529. https://doi.org/10.1080/10286020600782538

[46] Bombardelli, E. and Morazzoni, P. (1997) Curcubita pepo L. Fitoterapia, 68, 291. 
[47] Lazos, E.S. (1986) Nutritional, Fatty Acids and Oil Characteristics of Pumpkin and Melon Seeds. Journal of Food Science, 51, 1382-1383. https://doi.org/10.1111/j.1365-2621.1986.tb13133.x

[48] Fissore, E.N., Matkovic, L., Wider, E., Rojas, A.M. and Gerschenson, L.N. (2009) Rheological Properties of Pectin-Enriched Products Isolated from Butternut $(\mathrm{Cu}-$ curbita moschata Duch ex Poiret). LWT-Food Science and Technology, 42, 1413 1421. https://doi.org/10.1016/j.lwt.2009.03.003

[49] Rössner, S., von Zweigbergk, D., Ohlin, A. and Ryttig, K. (1987) Weight Reduction with Dietary Fibre Supplements: Results of Two Double-Blind Randomized Studies. Acta Medica Scandinavica, 222, 83-88. https://doi.org/10.1111/j.0954-6820.1987.tb09933.x

[50] Burslem, J., Schonfeld, G., Howald, M.A., Weidman, S.W. and Miller, J.P. (1978) Plasma Apoprotein and Lipoprotein Lipid Levels in Vegetarians. Metabolism, 27, 711-719. https://doi.org/10.1016/0026-0495(78)90009-4

[51] Anderson, J.W., Smith, B.M. and Gustafson, N.J. (1994) Health Benefits and Practical Aspects of High-Fiber Diets. The American Journal of Clinical Nutrition, 59, 1242S-1247S. https://doi.org/10.1093/ajcn/59.5.1242S

[52] Crowther, M.A. (2005) Pathogenesis of Atherosclerosis. Hematol. Hematology, ASH Education Program, 436-441. https://doi.org/10.1182/asheducation-2005.1.436

[53] Hu, Y.M., Li, L.Y., Jiang, H.C., Liu, Q.Z., Qu, L.S. and Huang, M.Y. (2008) Comparison of Lycopene and Fluvastatin Effects on Atherosclerosis Induced by a Highfat Diet in Rabbits. Nutrition, 24, 1030-1038. https://doi.org/10.1016/j.nut.2008.05.006

[54] Lamarche, B., Tchernof, A., Moorjani, S., Cantin, B., Dagenais, G.R. and Lupien, P. J. (1997) Small, Dense Low-Density Lipoprotein Particles as a Predictor of the Risk of Ischemic Heart Disease in Men. Prospective Results from the Quebec Cardiovascular Study. Circulation, 95, 69-75. https://doi.org/10.1161/01.CIR.95.1.69

[55] Aviram, M. and Fuhrman, B. (1998) Polyphenolic Flavonoids Inhibit Macrophagesmediate Oxidation of LDL-c and Attenuate Atherogensis. Atherosclerosis, 137, 545-550. https://doi.org/10.1016/S0021-9150(97)00306-7

[56] Sedigheh, A., Jamal, M.S., Mahbubeh, S., et al. (2011) Hypoglycaemic and Hypolipidemic Effects of Pumpkin (Cucurbita pepo L.) on Alloxan-Induced Diabetic Rats. African Journal of Pharmacy and Pharmacology, 5, 2620-2626. https://doi.org/10.5897/AJPP11.635

[57] Romero, A.L., West, K.L., Zern, T. and Fernandez, M.L. (2002) The Seeds from plantago ovata Lower Plasma Lipids by Altering Hepatic and Bile Acid Metabolism in Guinea Pigs. The Journal of Nutrition, 132, 1194-1198. https://doi.org/10.1093/jn/132.6.1194

[58] Lecumberri, E., Goya, L., Mateos, R., Alia, M., Ramos, S., Izquierdo-Pulido, M. and Bravo, L. (2007) A Diet Rich in Dietary Fiber from Cocoa Improves Lipid Profile and Reduces Malondialdehyde in Hypercholesterolemic Rats. Nutrition, 23, 332-341. https://doi.org/10.1016/j.nut.2007.01.013

[59] Takada, R., Saitoh, M. and Mori, T. (1994) Dietary Gamma Linolenic Acidenriched Oil Reduces Body Fat Content and Induces Liver Enzyme Activities Relating to Fatty Acid Beta Oxidation in Rats. The Journal of Nutrition, 124, 469-474. https://doi.org/10.1093/jn/124.4.469

[60] Fernandez, M.L., Trejo, A. and McNamara, D.J. (1990) Pectin Isolated from Prickly Pear (Opunita sp.) Modifies Low Density Lipoprotein Metabolism in Cholesterol-Fed Guinea Pigs. The Journal of Nutrition, 120, 1283-1287. 
https://doi.org/10.1093/jn/120.11.1283

[61] Gomathy, R., Vijayalakshmi, N.R. and Kurup, P.A. (1989) Hypolipidemic Principle of Inflorescence Stalks of Plantain (Musca sapientum). Journal of Biosciences, 14, 301-309. https://doi.org/10.1007/BF02716691

[62] Pal, S., Ho, N., Santo, S.C., Dubois, P., Mamo, J., Croft, K. and Allister, E. (2003) Red Win Polyphenolics Increase LDL Receptor Expression and Activity and Suppress the Secretion of Apo B100 from Human hepG2 Cells. Nutrition, 133, 100-109. https://doi.org/10.1093/jn/133.3.700

[63] Hamissou, M., Smith, A.C., Carter Jr., R.E. and Triplett, J.K. (2013) Antioxidative Properties of Bitter Gourd (Momordica charantia) and Zucchini (Cucurbita pepo). Emirates Journal of Food and Agriculture, 25, 641-647.

https://doi.org/10.9755/ejfa.v25i9.15978

[64] Martínez-Valdivieso, D., Font, R., Fernández-Bedmar, Z., Merinas-Amo, T., Gómez, P., Alonso-Moraga, Á. and del Río-Celestino, M. (2017) Role of Zucchini and Its Distinctive Components in the Modulation of Degenerative Processes: Genotoxicity, Anti-Genotoxicity, Cytotoxicity and Apoptotic Effects. Nutrients, 9, 755.

https://doi.org/10.3390/nu9070755 